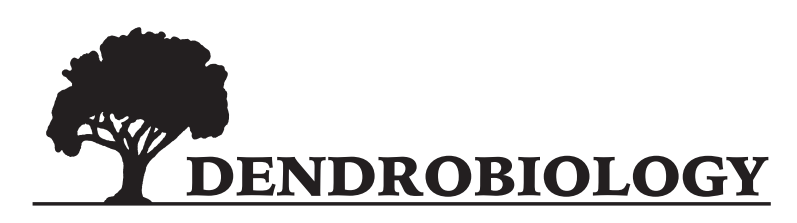

2020, vol. $83,43-51$

http://dx.doi.org/10.12657/denbio.083.004

\begin{abstract}
Bo Zhou*, Dan Peng, Qingxin Zhao, Shiyu Yangnan, Shiquan Yang, Feng Yang, Gaoyi Qu, Weiwei Tang, Jianping Ou, Wenhua Xiang, Jianlin Xiang, Xiangwen Deng*
\end{abstract}

\title{
Improvements in timber production of Chinese fir (Cunninghamia lanceolata) per unit forest area in China via tree breeding: Status and challenges
}

Received: 10 February 2020; Accepted: 29 May 2020

\begin{abstract}
Chinese fir [Cunninghamia lanceolata (Lamb.) Hook] is a fast-growing tree species that is widely planted for timber production in southern China. Many high-quality breeding systems for Chinese fir have been developed using genetic methods. Here, we systematically review progress in increasing Chinese fir timber volumes per unit forest area in China, using genetic methods. We comprehensively assess the objectives, strategies, and primary accomplishments of the first to fourth generations of a Chinese fir breeding program. Furthermore, we propose a genetic improvement program and protocol for Chinese fir, and outline several recommendations with respect to the main challenges associated with using genetic methods to increase timber yields. Finally, we present a series of proposals to increase Chinese fir timber production in China. This review offers insight into genetic improvements that have increased timber volumes of Chinese fir over four generations of breeding, and provides direction for future genetic improvements to wood properties.
\end{abstract}

Keywords: Cunninghamia lanceolata, genetic improvement, timber volumes per unit forest area, recommendations, wood properties, proposals

Addresses: B. Zhou, D. Peng, Q.X. Zhao, S.Y. Yangnan, S.Q. Yang, F. Yang, G.Y. Qu, W.W. Tang, J.P. Ou, W.H. Xiang, J. L. Xiang, X.W. Deng, Faculty of Life Science and Technology, Central South University of Forestry and Technology, Changsha 410004, Hunan Province, China, e-mail: zhoubo8888899999@163.com and dxwfree@126.com.

B. Zhou, X.W. Deng, National Engineering Laboratory of Applied Technology for Forestry and Ecology in Southern China, Changsha 410004, Hunan, China

B. Zhou, W.H. Xiang, X.W. Deng, Huitong National Station for Scientific Observation and Research of Chinese Fir Plantation Ecosystem in Hunan Province, Huitong, 438107, China

B. Zhou, D. Peng, Forestry Biotechnology Hunan Key Laboratories, Hunan Changsha, 410004, China J. L. Xiang, State Administration of Ying Zui Jie National Nature Reserve, 418000, Huitong, Hunan, China

*Corresponding authors 


\section{Introduction}

Chinese fir [Cunninghamia lanceolata (Lamb.) Hook] is one of the most significant and fastest growing coniferous tree species in southern China, accounting for approximately $20-30 \%$ of commercial timber production in the country (Huang et al., 2012; Wan et al., 2012; Ma et al., 2016). At present, the species is grown commercially in 17 provinces and cities in China south of the Qinling Mountains and the Huaihe River, with production centered in Hunan, Guangxi, Jiangxi, and Fujian Provinces (Wei et al., 2017). Currently, Chinese fir plantations occupy 10,960,000 (Fig. 1) ha of land in China, and have produced more than $72,600,000 \mathrm{~m}^{3}$ of timber (Wei et al., 2017). Results of the third (1984-1988), sixth (1999-2003), and eighth (2009-2013) forestry inventories indicate that the forested area and timber stock of Chinese fir are the largest among economically-important tree species in China (Fig. 2 ). Results of the sixth forestry inventory indicate that total plantation area had reached $12,930,000$ ha (Fig. 2A), while the eighth inventory reported a total timber volume of 7,260,000 $\mathrm{m}^{3}$ (Fig. 2B). The sixth inventory also indicated that Chinese fir accounted for $26.3 \%$ (Fig. 2C) of the total plantation area and $46.9 \%$ (Fig. 2D) of the total timber volume. Chinese fir timber is highly resistant to termites and decay, as evidenced by many well-preserved Chinese fir wood products, and is primarily used in the construction of houses, furniture, coffins, bridges, and ships. Chinese fir has been improved by breeding over several generations, resulting in good quality timber and fast-growing, stress resistant trees (Ye et al., 1981; Fan, 2012).

Natural fir has been used in China since ancient times. Chinese fir was used by the Yue people to build houses during the early Neolithic, and for coffins and ship building during the Qin Dynasty (Lin \& Zhang, 2007). When natural fir supplies were no longer sufficient to meet societal demands, the ancient Chinese began planting the species. At present, Chinese fir represents one of the most important industrial and commercial sources of coniferous evergreen timber in China (Shi \& Zheng, 2010; Huang et al., 2012; Ma et al., 2016). Moreover, the bark of Chinese fir is an important traditional medicine for treating boils and fungal infections of the feet. Planted Chinese fir also improves the environment, beautifies natural landscapes and cultural environments, and provides other ecosystem services.

In this article we review the history of genetic improvement of Chinese fir in China, and summarize the research outcomes of the first, second, and third generations of genetic improvements aimed at increasing timber yield. Furthermore, we

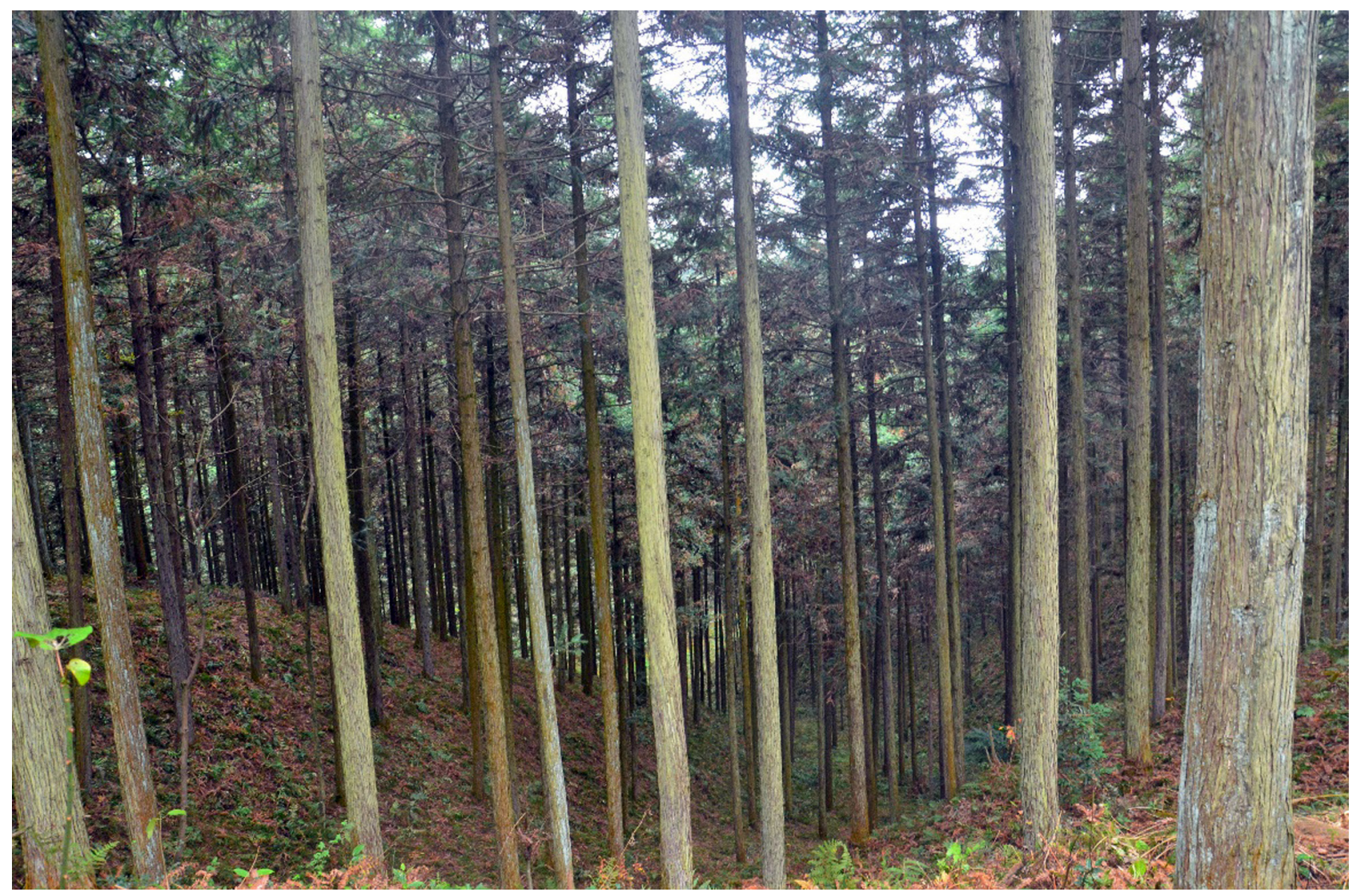

Fig. 1. An artificial Chinese fir forest 


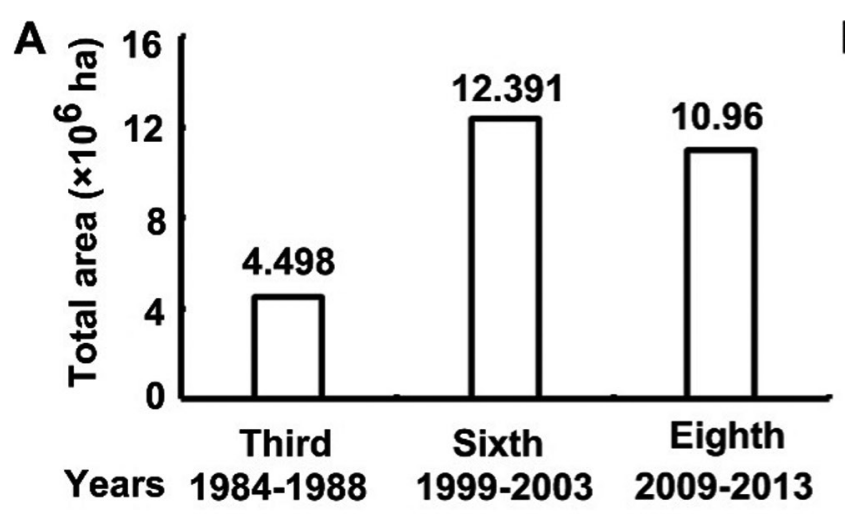

B
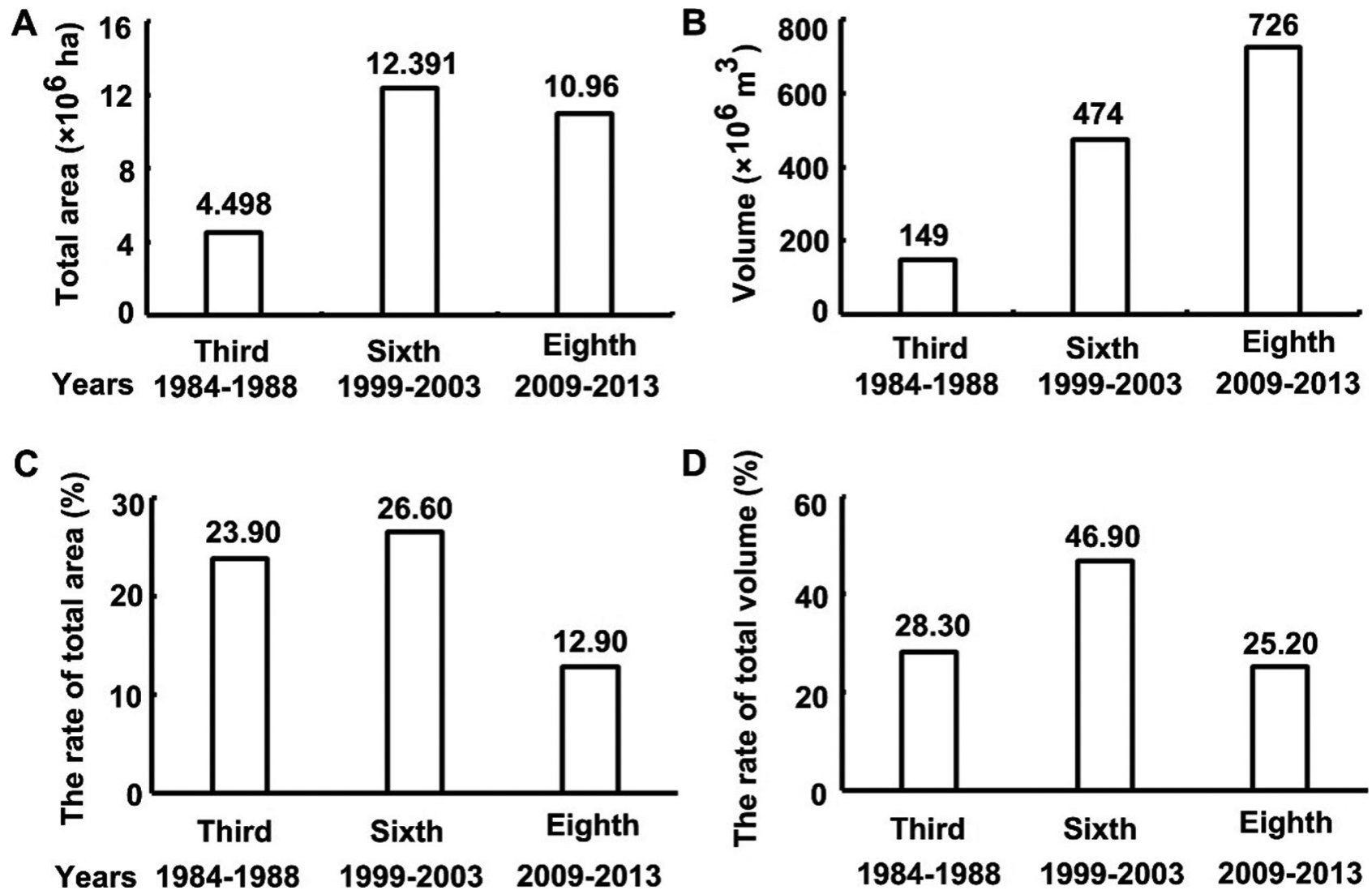

Fig. 2. Chinese fir is the largest planted tree species in China

$\mathrm{A}$ - the total plantation area of Chinese fir in China; B - the timber volume Chinese fir in China; C - the rate of the total plantation area of Chinese fir in China; D - the rate of the timber volume Chinese fir in China.

summarize the genetic improvement program and protocols for Chinese fir. Finally, we provide recommendations for expanding the cultivated area of Chinese fir, and for improving timber quantity.

\section{The Chinese fir genetic improvement program}

Protocols for genetic improvements for increasing the timber volume of Chinese fir per unit forest area are described in Figure 3. These protocols present a clear process for increasing timber volumes using genetic methods (Chen \& Shi, 1983). The protocol begins by exploring existing genetic methods and documenting the genetic background of seedling plantations to identify high-quality clones. Based on existing genetic test plantations, forest scientists can identify high-quality individuals by screening superior provenances, families, or clones. Fourteen types of superior clones have been selected based on the genetic test plantation, and eight lines were selected from each type, for a total of 112 clones. Each clone type serves as both the male and female parent in mating. Two-level diallel cross mating of each type was performed using the following two combinations (Chen \& Shi, 1984): (1) four lines of each type male parent as male parent $\times$ four lines of each type female parent as female parent and (2) four lines of each type female parent as male parent $x$ four lines of each type male parent as female parent. One hundred flowers were fertilized in each line for each type of mating, and fertilized flowers were covered with parchment bags prior to seed formation. Mating yielded 49 mated combinations and 224 seed types. Seeds were then sown, and 10 high-quality seedlings of each mating were screened after one year of growth, then transplanted. Planting distance was $2 \times$ 2 m (length $\times$ width). Timber volumes $\left(h^{-1}\right)$ were tested four and seven years after planting, and genetic gains were assessed. Forty straight, tall clones with superior timber volumes were then selected from the transplanted individuals to establish a productive seed orchard, and 500 superior clones were selected to establish a next-generation genetic improvement seed orchard. We also considered anthracnose resistance during selection.

The multi-generation genetic program for improving timber yields is presented in Figure 4, including both the main program and the subprogram (Chen \& Shi, 1983). The main program has two primary objectives: developing and improving breeding populations, and selecting high-quality varieties for wood production from the improved breeding stock. 


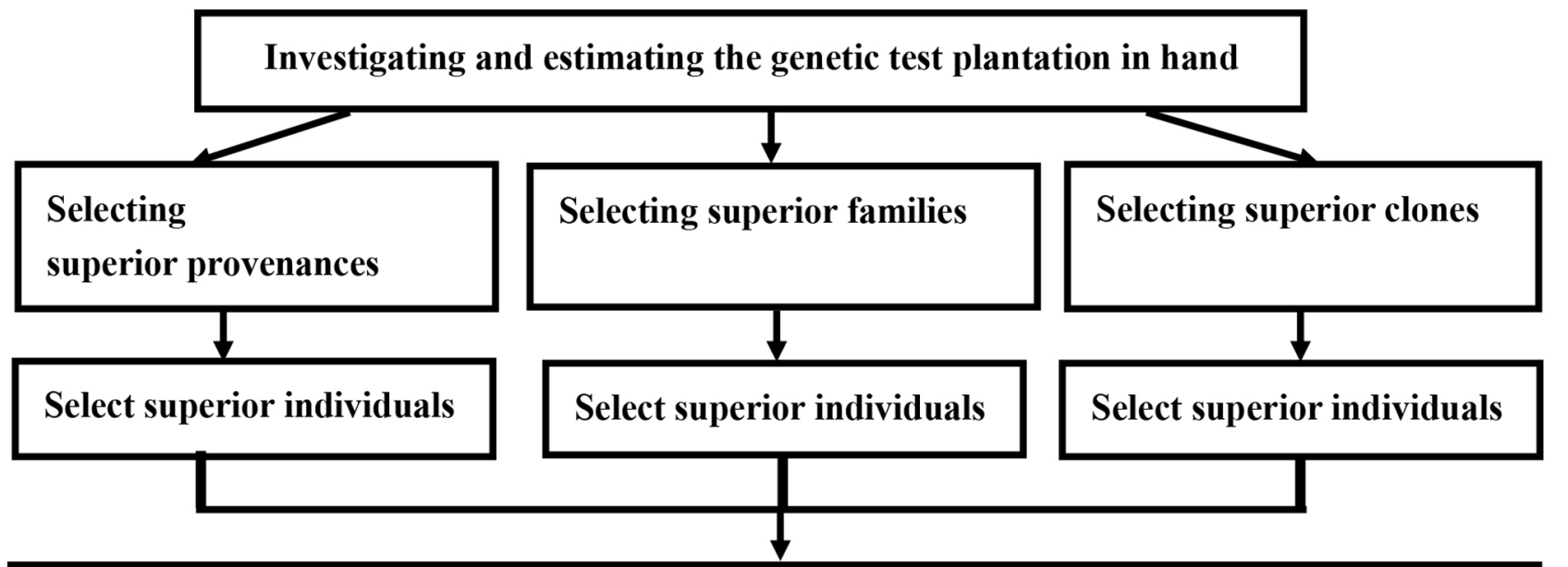

Select about 14 types of superior clone. Each type has 8 lines. Each type of clone not only as male parent but also as female parent in mating. Two-level diallel-cross mating were preformed: (1) 4 lines of each type male parent as male parent $\times 4$ lines of each type female parent as female parent; (2) 4 lines of each type female parent as male parent $\times 4$ lines of each type male parent as female parent.

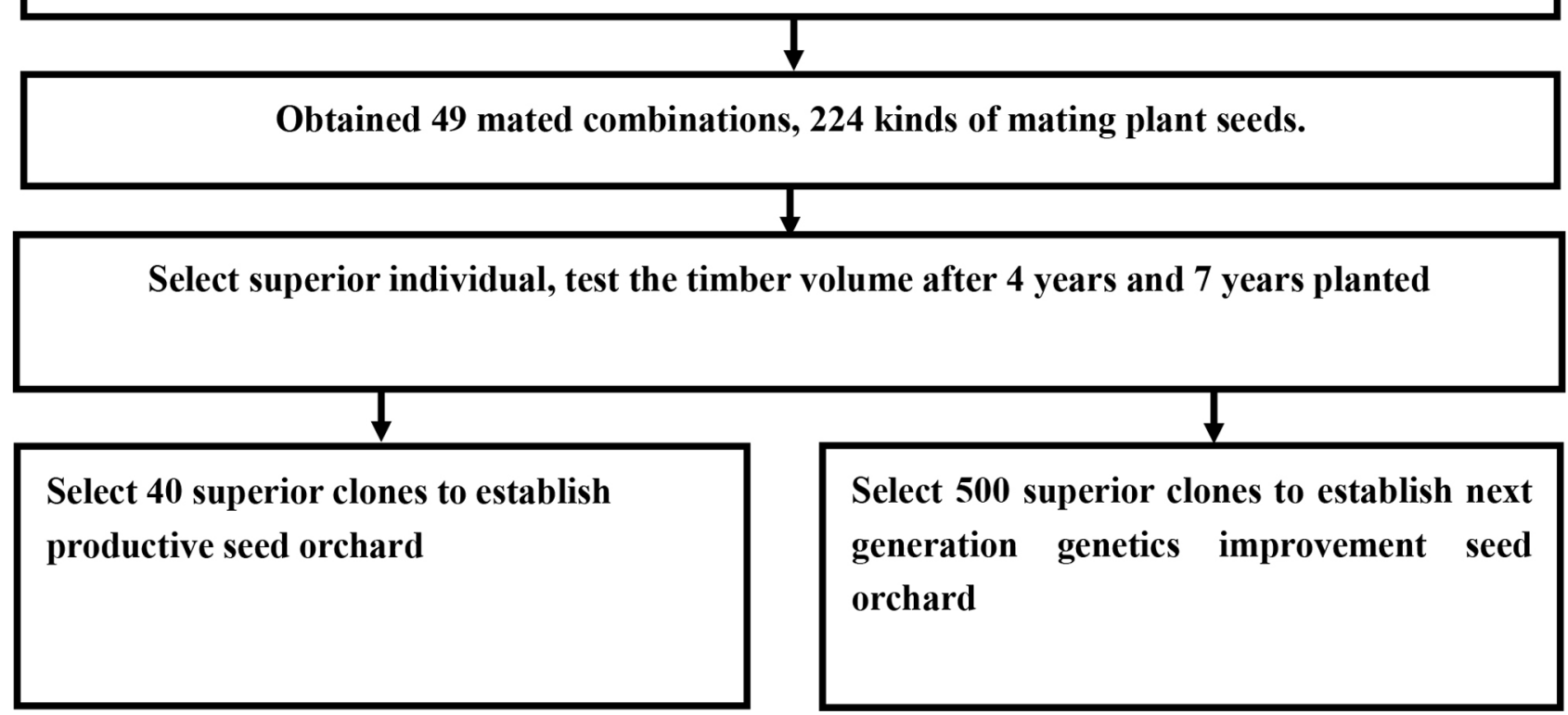

Fig. 3. The genetic improvement protocol of Chinese fir

The improvement of breeding stock is achieved primarily by selecting excellent individuals from semi-natural and semi-artificial Chinese fir stands, and making improvements over three successive generations. Correspondingly, the production group is formed by establishing three generations of seed orchards for mass production; each generation of seed orchards is established by testing and selecting the offspring of previous generations of the breeding population. The subprogram is focused on identifying high-quality individuals and superior mating combinations from unimproved forests, producing zone standing forest, and mate origin to be continually supplemented to the breeding populations of the second and higher generations in the main program. The main program and the subprogram are conducted simultaneously. The subprogram supplements each generation of the main program, and contributes to enhanced genetic diversity and desired traits, such as increased drought resistance, in fourth generation plants. 


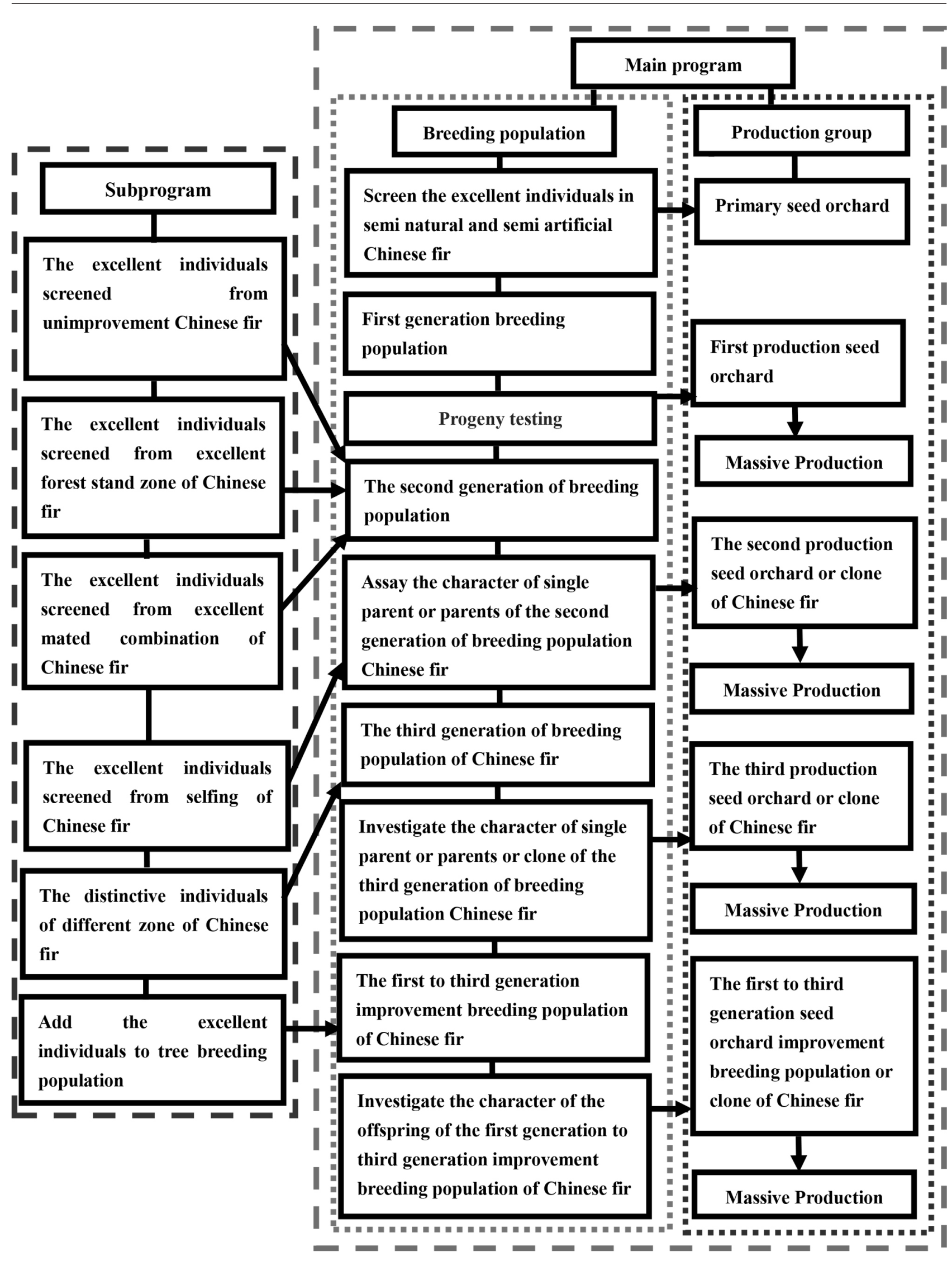

Fig. 4. The genetic improvement program of multi generation of Chinese fir 


\section{Achievements of the improvement program}

Genetic improvements to increase timber yields has been pursued over four generations, with each generation having its own direction and focus. The schedule, objectives, strategies, and achievements of each generation are shown in Table 1. The first generation of genetic improvement began in 1959 and ended in 1975, and the second and third generations occurred in 1976-2002 and 2003-2018, respectively. The fourth generation was launched in 2019 and remains underway. The objective of the first generation was to select strains with high timber yields and resistance to biotic and abiotic stress. It is worth noting that patterns of geographic variation must be taken into account in the selection process, as latitude affects phenotypic traits in Chinese fir; e.g., latitudinal variations result in variations in climate and temperature, and phenotypic traits change in response to these conditions (Chen \& Shi, 1983; Ye et al., 1991). However, no variations in the main traits of Chinese fir were distinguishable along north-south or east-west gradients in China; rather, variations have evolved gradually on either side of the Nanling Mountains. However, regional subpopulations exhibit significant genetic differences, and variation in important economic traits was high among subpopulations $(\sim 10 \%$ or greater) (Chen, 2001; Zheng et al., 2012; Duan et al., 2016). Based on these conditions, the strategy of the first generation focused on the selection of focal traits, such as height, diameter at breast height, bark thickness, timber volume, heartwood ratio, and wood density, along with trait screening to enhance production. More than 500 high-quality individuals from superior provenances were screened in the first generation, and families or clones in hand in Nanping, Longyan, and Sanming cities, Fujian province, where seed orchards were established on 244.7 ha of land (Zheng \& Shi, 2006), ultimately comprising the first generation of breeding stock. These high-quality individuals were then mated using two-level diallel cross mating, and superior offspring were selected for use in the second generation. Studies of these first genetic improvements focused primarily on hereditary capacity (in the narrow sense), genetic correlations, and genotype-environment interactions.

Compared to the first generation, increases in timber volumes in the second generation of improvement were $>25 \%$ (Shi, 1994). In the second generation, 358 superior individuals were used for breeding (Shi, 1994) and 303.3 ha of seed orchard were established (Zheng \& Shi, 2006). With respect to the current status of the second generation, breeding and production orchards require further improvement, and high-quality raw genetic materials from 300-500 trees should be reserved for the

Table 1. The breeding objectives, strategies and achievements of genetics improvement from the first generation to the fourth generation of Chinese fir in China

\begin{tabular}{|c|c|c|c|c|}
\hline Generation & Objectives & Strategies & Achievements & Breeding zones \\
\hline $\begin{array}{l}\text { First } \\
(1959-1975)\end{array}$ & $\begin{array}{l}\text { Screen high timber yield prod- } \\
\text { uct lines, increases 15\%'s timber } \\
\text { volume yield and enhance stress } \\
\text { resistant }\end{array}$ & $\begin{array}{l}\text { Measure while select- } \\
\text { ing excellent individ- } \\
\text { ual from unimproved } \\
\text { Chinese fir forest. }\end{array}$ & $\begin{array}{l}\text { Screened over } 500 \text { excellent } \\
\text { individual lines, investigated } \\
\text { the genetic gains, genotype and } \\
\text { environment co-work ability. } \\
\text { Compared with the unimproved } \\
\text { Chinese fir, the timber volume } \\
\text { yield per hectare increased } 15 \% \text {. }\end{array}$ & $\begin{array}{l}\text { Fujian Province of } \\
\text { China }\end{array}$ \\
\hline $\begin{array}{l}\text { Second } \\
(1976-2002)\end{array}$ & $\begin{array}{l}\text { Compared with the first improve- } \\
\text { ment generation, the timber volume } \\
\text { yield enhances } 25 \% \text {. enhance stress } \\
\text { resistant, improve breeding orchard } \\
\text { and timber product seed orchard. }\end{array}$ & $\begin{array}{l}\text { Screen the excellent } \\
\text { individual lines from } \\
\text { first-generation im- } \\
\text { proved progeny forest. }\end{array}$ & $\begin{array}{l}\text { Screened } 344 \text { excellent individ- } \\
\text { ual lines. Compared with the } \\
\text { first improved generation, the } \\
\text { timber volume yield per hectare } \\
\text { increased } 15-25 \% \text { (Shi, 1994). }\end{array}$ & $\begin{array}{l}\text { Fujian, Yunnan, } \\
\text { Guangxi, Hunan, } \\
\text { Jiangxi and Guizhou } \\
\text { Province of China }\end{array}$ \\
\hline
\end{tabular}
Screening 300-500 excellent individual lines as the improvement material of next generation.

Third Compared with the second improve-

(2003-2018) ment generation, timber volume yield increases $5 \%$; improve the environment resistant ability, the sexual multiplication and asexual reproduction ability should be excellent. Screen the special useage breeding.

Fourth Compared with the third improved (2019-) generation, timber volume yield increases $5 \%$; enhance the wood properties, further enhance the ability of resistant drought or soil nutrition depletion.
Screen the excellent individual lines from second-generation improved progeny forest.

Screen the excellent individual lines from third-generation improved progeny forest.
Screened 382 excellent individu- Fujian, Yunnan, al lines, constructed 40 subfam- Guangxi, Hunan, ilies; Screened 50 lines which Jiangxi and Guizhou contains perfect genotype. Com- Province of China pared with the second improved generation, the timber volume yield per hectare increased 18-19\% (Jiang, 2018). 
next generation of screening to develop the third generation breeding population of trees. The breeding population comprises a single-parent progeny forest, a full-sib families forest, a provenance forest, and an unimproved artificial forest, from which more than 300 high-quality genetic resources have been screened.

The objectives of the third generation included increasing timber volumes by more than $5 \%$ over the second generation, enhancing environmental adaptability of trees, increasing sexual and asexual reproductive ability, and increasing growth capacity, with distinct phenotypes and/or specific applications (Yu, 2008). However, the breeding population in the third generation, which comprised 291 individuals, was derived from a second generation progeny forest, a mate-origin progeny forest, a national high-quality family regional experimental forest, a multiple-line mate experimental forest, and a two-level diallel cross experimental forest (Zheng et al., 2018). For this generation, 430 ha of seed orchard were established (Zheng et al., 2018), and more than 380 genetic resources were screened from the experimental forests and used to establish 40 breeding sublines, each of which included six to eight parents. After mating was performed within sublines, superior clones were selected for the next generation. Furthermore, one elite group derived from 50 superior genotypes was developed and added to the third-generation seed orchard.

The objectives of the fourth generation include an additional $5 \%$ increase in timber volumes compared with third generation, and the expanded use of germplasm resources for breeding and improvement of wood traits. A fourth-generation seed orchard is being established at the Yangkou forestry station in Fujian Province using high-quality third generation plants. The total planting area of seed orchards for this generation is not yet available. Further efforts are required to improve stress resistance, particularly with respect to drought tolerance and leanness-resistance. The breeding population in this generation is expected to comprise approximately 500 high-quality plants from the third-generation progeny forest, as well as high-quality individuals from the first and second generations and from an unimproved artificial forest. The highlight of this generation is the creation and application of new breeding techniques for improving traits of Chinese fir.

Three generations of genetic improvement of Chinese fir have been realized as of 2018, and the fourth generation is underway. Substantial improvement has been made with respect to timber volume per unit forest area over the previous three generations.

\section{Current issues, future directions, and challenges in promoting increased timber volume per unit forest area}

Key issues associated with the genetic improvement of timber volume per unit forest area are as follows: first, increases in timber volume per hectare became less and less minor after three generations using current breeding technology. Second, owing to the lack of an efficient gene transfer system for Chinese fir, it is difficult to create new varieties by means of genetic modification. Third, the genome of Chinese fir has not yet been fully sequenced, and many functional genes, particularly those involved in the regulation of wood formation, have been difficult to identify and characterize. Fourth, the present breeding objective is very simple and focuses on enhancing a single character, which may lead to difficulties in meeting market demands.

The program has identified eight objectives for future work. The first is to control genetic relationships and avoid mating of closely related individuals, focusing instead on mating distantly related individuals to maximize gains in timber volume in offspring. Second, construct a database and genetic prediction model for Chinese fir to estimate increases in timber volume per unit forest area. Third, expand the combined use of traditional and molecular breeding technologies. Chinese fir can be systematically improved using molecular methods, whereas traditional breeding methods cannot achieve this same end. Molecular breeding technology is supplementary to the traditional breeding method. A fourth objective is to use screening to identify breeds resistant to specific abiotic and biotic stresses, such as high temperatures and spot anthracnose. A fifth objective is to sequence the genome of Chinese fir to identify genes with special functions. In addition, the program intends to establish a highly efficient protocol for investigating gene function. For example, a somatic embryogenesis method (Pullman et al., 2016) might be used to prepare plant callus for isolating protoplasts, which could be transformed and used to regenerate transgenic Chinese fir plants (Lin et al., 2014; Chen et al., 2019). The seventh objective is to use transgenic techniques to insert genes regulating desired traits, such as insect resistance, anthracnose resistance, or drought resistance, into Chinese fir. The final objective is to breed varieties with traits that meet market demands, such as high per unit area timber volumes, drought resistance, and salt resistance. 


\section{Conclusion}

We have demonstrated that timber volume per unit forest area has increased as a result of genetic improvements between the first and fourth generations of the Chinese fir breeding program in China. In addition, we have summarized the main challenges in increasing timber yield per unit area, and provided solutions and recommendations for future work.

\section{Acknowledgments}

This work was supported by The National Key Research and Development Program of China (2016YFD0600303), the National Training Program of Innovation and Entrepreneurship for Undergraduates of China (201510538004), the Undergraduates students research and innovative experiment program of Hunan province of China (2015011), the Foundation of the Project for national innovation and entrepreneurship training program for College Students (S201910538014), the Scientific Research Foundation of Hunan Education Department of China $(18 C 0279,19 A 528)$, the Scientific Innovation Fund for Post-graduates of Central South University of Forestry and Technology of China (CX20192055), the Undergraduates students research and innovative experiment program of Hunan province of China (201907), the Undergraduates students research and innovative experiment program of Central South University of Forestry and Technology of China (201981).

\section{References}

Chen H, Wang JP, Liu HZ, Li HY, Lin YCJ, Shi R, Yang CM, Gao JH, Zhou CG, Li QZ, Sederoff RR, Li W \& Chiang VL (2019) Hierarchical transcription factor and chromatin binding network for wood formation in Populus trichocarpa. The Plant Cell 31: 602-626. doi:10.1105/tpc.18.00620.

Chen YW \& Shi JS (1983) Some fundamental problems in genetic improvement Chinese fir. Journal of Nanjing Technological College of Forest Products 4: 5-19.

Chen YW \& Shi JS (1984) Some fundamental problems in genetic improvement Chinese fir (continue). Journal of Nanjing Technological College of Forest Products 1: 1-15.

Chen DX (2001) Review on the progress of genetic improvement of forest trees in China. Guang xi Forestry Science 30: 13-17.

Duan HJ, Cao S, Zheng HQ, Hu DH, Lin J, Zhang XW, Zhang XY, Chen P, Sun YH \& Li Y (2016) Variation analysis on the main economic charac- ters of Chinese fir clones. Journal of Southwest Forestry University 36: 78-83.

Fan FJ (2012) Study on growth traits difference among clones of Chinese fir. Anhui Agriculture Science Bulletin 18: 21-24.

Huang HH, Xu LL, Tong ZK, Lin EP, Liu QP, Cheng LJ \& Zhu MY (2012) De novo characterization of the Chinese fir (Cunninghamia lanceolata) transcriptome and analysis of candidate genes involved in cellulose and lignin biosynthesis. BMC Genome 13: 648. doi:10.1186/1471-2164-13-648.

Jiang H (2018) Early growth analysis of 3rd generation superior families in Chinese fir. Fujian Lin Ye 27-32.

Lin YC, Li W, Chen H, Li QZ, Sun YH, Shi R, Lin CY, Wang JP, Chen HC, Chuang L, Qu GZ, Sederoff RR \& Chiang VL (2014) A simple improved-throughput xylem protoplast system for studying wood formation. Nature Protocols 9: 2194-2205. doi:10.1038/nprot.2014.147.

Lin YD \& Zhang CX (2007) The brief history of cultivating Cunninghamia lanceolata in China. Journal of Dialectics of Nature 29: 79-82.

Ma ZH, Huang BL, Lin SZ, Cao G, Ding G \& Lin S (2016) Ion flux in roots of Chinese Fir (Cunninghamia lanceolata (Lamb.) Hook) under Aluminum stress. PLOS ONE 11: e0156832. doi:10.1371/ journal.pone.0156832.

Pullman GS, Olson K, Fischer T, Egertsdotter U, Frampton J \& Bucalo K (2016) Fraser fir somatic embryogenesis: high frequency initiation, maintenance, embryo development, germination and cryopreservation. New Forests 47: 453-480. doi:10.1007/s11056-016-9525-9.

Shi JS (1994) The present situation of Chinese fir genetic improvement in Fujian province and the technical countermeasures of development it. Journal of Fujian Forestry Science \& Technology 21: 28-31.

Shi JS, Zhen Y \& Zheng RH (2010) Proteome profiling of early seed development in Cunninghamia lanceolata (Lamb.) Hook. Journal of Experimental Botany 61: 2367-2381. doi:10.1093/jxb/erq066.

Wan LH, Wang F, Guo XQ Lu SF, Qiu ZB, Zhao YY, Zhang HY \& Lin JX (2012) Identification and characterization of small non-coding RNAs from Chinese fir by high throughput sequencing. BMC Plant Biology 12: 146. doi:10.1186/1471-222912-146.

Wei XY, Wang SY, Chen AL Ye YQ, Huang TS \& Cao GQ (2017) Physilolgical response of different allelopathic types of Chinese fir clones to continuous cropping obstacles soil. Journal of Forest and Environment 37: 22-28.

Ye PZ, Chen YW \& Ruan YC (1981) Estimates of genetic gains from the seed orchard of Chinese fir (Cunninghamia lanceolata Hook.). Journal of Nan- 
jing Technological College of Forest Products 2: 33-48.

Ye ZH, Shi JS, Wen YZ, Li SM, Yu RZ \& Chen RX (1991) Geographic variation and in heritance, correlation and selection of traits of provenances of Chinese fir. Journal of Nanjing Forestry University 15: 7-10.

Yu RZ (2008) Study on establishing Cunninghamia lanceolata breeding poputation of the third generation. Journal of Fujian College of Forestry 28: 69-72.

Zheng HQ, Liang R, Hu DH, Wei RP, Wang RH \& Yan S (2012) Selection of large-sized Cunninghamia lanceolata superior trees and variation analysis on the major economic traits. Journal of Southwest Forestry University 32: 26-29.

Zheng RH \& Shi JS (2006) Breeding status and prospect of superior Chinese fir in Fujian province. The Third Southern Forest Breeding Conference 12-19.

Zheng RH, Shi JS, Su SD, Lin HZ, Lin JC, Fang LM \& Ye DQ (2018) The establishment technique and application of the third generation seed orchard of Chinese fir. Journal of Forest and Environment 38: 406-413. 